\title{
Ictal laughter: a case report with clinical, cinefilm, and EEG observations
}

\author{
FRANCES R. AMES AND OSCAR ENDERSTEIN
}

\author{
From the Department of Neurology, Groote Schuur Hospital, Capetown, South Africa
}

SYNOPSIS Seizures with laughter, verbalization, and repetitive abduction-adduction movements of the upper limbs are described in a 13 year old male of normal intelligence. Cinéfilm and EEG records illustrate some of the points made in the text.

It is just over 100 years since Trousseau (1873) first described laughter as an ictal phenomenon. The subject has recently been reviewed by several authors (Gumpert et al., 1970; Loiseau et al., 1971; Gascon and Lombroso, 1971; Swash, 1972; and Chen and Forster, 1973). Rey-Pias (1972) states that there are 'today approximately 120 reported cases although in almost one-half of them there is not sufficient information to justify their inclusion in this group'. Their rarity is emphasized by Chen and Forster (1973) who, in reviewing 5,000 consecutive cases of 'complex', and therefore selected epilepsies, found an incidence of only $0.20 \%$ of 'gelastic' epilepsy. The introduction of the term gelastic epilepsy by Daly and Mulder (1957) may have resulted in less precision in diagnosis. Mirth (gelos) does not necessarily include laughter. Smiling may be voluntary or barely perceptible, whereas the laryngeal and respiratory components of laughter are more likely to be involuntary and are definite. Inappropriate laughter is often due to diffuse cerebral disease. If, in addition, it is episodic and the patient has amnesia for it, it is likely to be ictal.

We report a patient with ictal laughter, not only because well-documented cases are uncommon, but also because cinefilm recordings during seizures revealed unusual movements of the upper extremities; tape recording during the seizure confirmed the clinical observation of stereotyped verbalization (the content of which seemed to indicate remembrance of past attacks) and on two occasions electroencephalographic (EEG) recording coincided with ictal laughter. (Accepted 11 July 1974).

\section{CASE HISTORY}

A white male of 13 years presented with unusual episodic behaviour for two months. His teacher reported that on several occasions 'he cleared his throat loudly in class'. This was interpreted as 'an attempt to gain attention', especially as his school work had deteriorated during the preceding term. About a week later his mother noticed that, several times a day, he would suddenly stare and 'be blank' for a few seconds, On many occasions this disturbance of consciousness would be accompanied by 'clearing of the throat and laughing in an embarrassed manner'. After 'laughing' he often said, 'Here we go again', put his hands together and 'went rigid'. These episodes lasted 10 to 15 seconds and he had no recollection of them. At night his parents often heard him making the same noise in his sleep'it sounds like a laugh and a whimper'. After one of these attacks in the early morning he fell out of bed and was found unconscious on the floor with his legs extended. After this he slept deeply for about an hour. At this stage his parents sought medical help, having dismissed the previous episodes as 'psychological and perhaps related to masturbation'. The patient said that he himself could not see any connection between masturbation and his attacks but suggested, 'I think the laughing attacks came about because $I$ listened to a radio programme in which one of the actors had a rather peculiar laugh. I thought it amusing and used to imitate the laugh when I was fooling around. This laugh must have just "come out" when I had an attack.'

He was the youngest of six children. Birth and developmental milestones were normal. For some years he had occasionally complained of generalized headaches that were diagnosed as 'migraine'. He had 11 


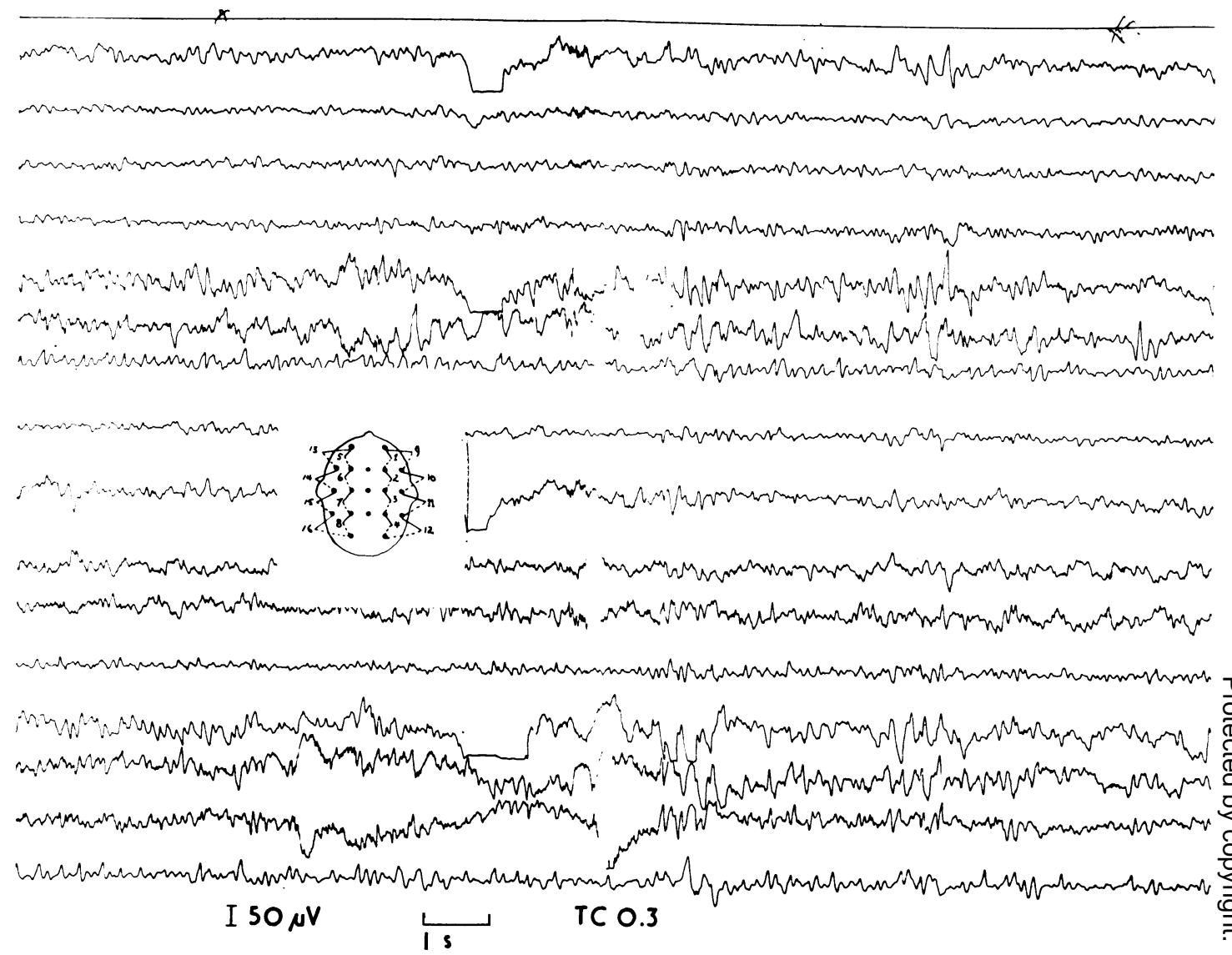

FIG. 1 Interictal record showing predominant left-sided abnormality.

week before his attacks manifested themselves. There was no family history of epilepsy.

General and neurological examination was normal. He was right-handed. Verbal IQ was 134 and performance IQ 100 . He appeared to have some impairment of short-term visual retention. Cerebrospinal fluid was normal. Lumbar pneumoencephalogram was normal. Two brain scans (24 September 1973 and 1 April 1974) were normal.

EEG The resting record showed a dominant frequency of $9 \mathrm{~Hz}$. This was symmetrical and blocked well. Occasional irregular sharp waves appeared in the right frontal leads but the most striking abnormality was episodic slow and sharp activity of increased amplitude on the left especially in the anterior temporal area (Fig. 1). This was accentuated by hyperventilation, which also provoked generalized high amplitude slowing. This persisted during intermittent photic stimulation. On one occasion he had a laughing attack during EEG recording. This lasted five seconds and, during it, initial general desynchronization was followed by generalized slowing most prominent frontally (Fig. 2). On another occasion, after a routine recording, the machine was switched off when he suddenly pushed back his chair, abducted his arms, and laughed for 60 seconds. The latter part of the attack was recorded and showed generalized slowing (2 to $3 \mathrm{~Hz}$ ) of high amplitude (Fig. 3).

On one occasion we cinefilmed and tape-recorded attacks during an hour of vigorous hyperventilation. Two laughing attacks occurred, the one lasting 20 and the other five seconds. A selected sequence of the five second attack is depicted (Fig. 4). The patient stopped hyperventilating and began to make clonic expiratory noises resembling laughter. This was followed by the clearly enunciated words, 'Here goes', and then a moan. As the noise began he flexed his elbows so that his hands, which had been resting on 


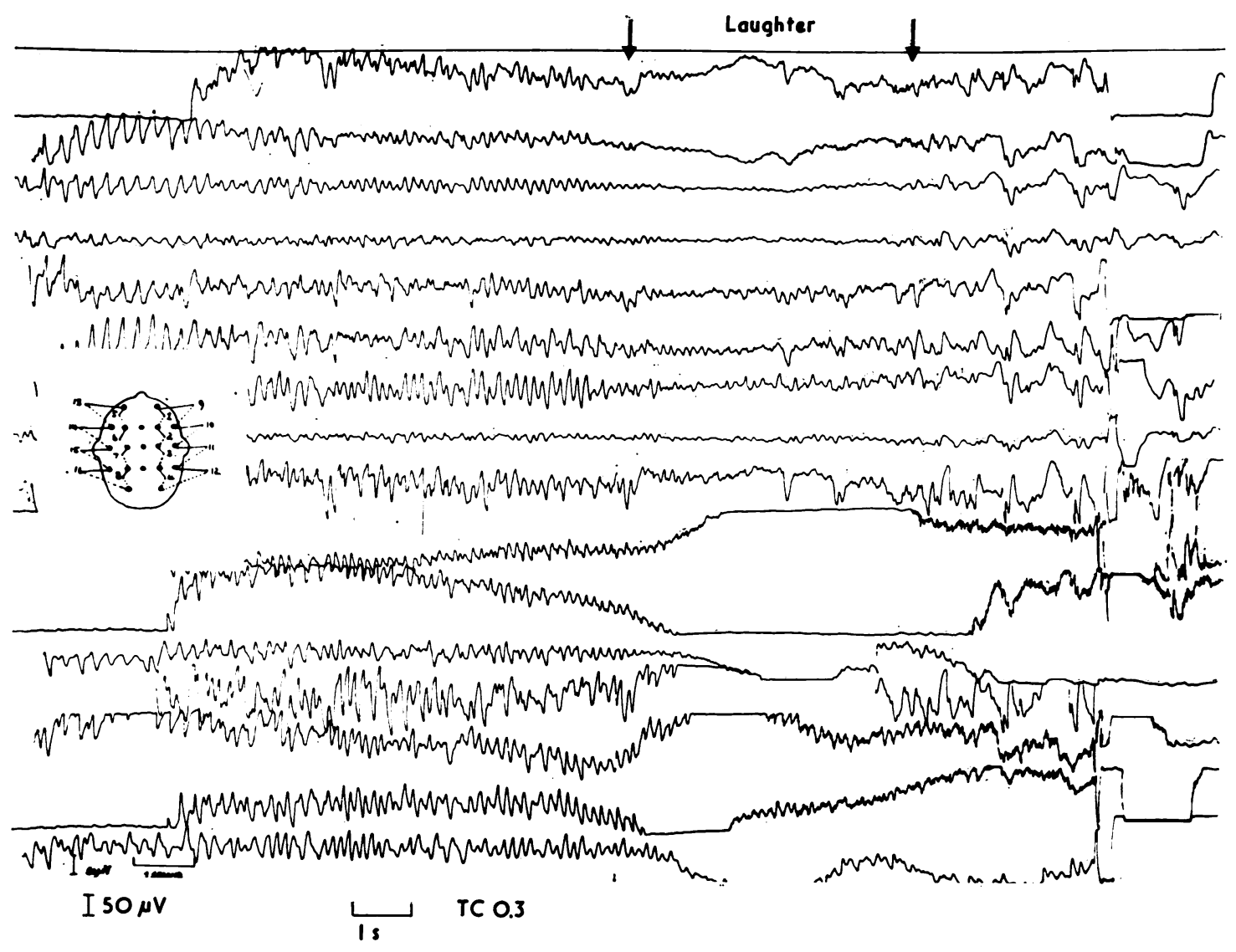

FIG. 2 EEG during a laughing attack. Note initial desynchronization followed by generalized slowing.

his thighs, touched each other. He then began to abduct and adduct his arms proximally, successively increasing the degree of abduction to about 45 degrees. Simultaneously he flexed and extended his wrists, turned his head to the left and his face became pale. His eyes remained open and he smiled slightly, but the poverty of facial movement contrasted strikingly with the vigour of the upper limb movements and the immobility of the lower limbs. He had complete amnesia for the whole attack.

During his stay in the ward the staff reported hearing him laugh during the day or in his sleep on many occasions. He was discharged on diphenylhydantoin $100 \mathrm{mg}$ and diazepam $2 \mathrm{mg}$ each three times daily. His parents and the school staff reported frequent attacks, during one of which he behaved 'automatically' for about 30 minutes. His school fellows mocked him for being 'mad'. Carbamazepine $100 \mathrm{mg}$ and diazepam $2 \mathrm{mg}$ thrice daily did not improve his condition but when he was placed on carbamaze- pine $200 \mathrm{mg}$ thrice daily and ethosuximide 250 $\mathrm{mg}$ twice daily his attacks decreased in frequency and now (eight months after their onset) his laughing attacks have disappeared but he still gets an occasional 'blank' lasting a few seconds. A recent EEG showed generalized slowing with virtually continuous $3-4 \mathrm{~Hz}$ slow and spike wave activity bifrontally.

\section{DISCUSSION}

In addition to the laughter, the unusual clinical features in this patient are the type of verbalization and the repetitive abduction-adduction movements of the upper extremities.

As far as the laughing is concerned, the explanation volunteered by him of his attention having been arrested by a particular contrived laugh, his repeated imitation of it, and its later 

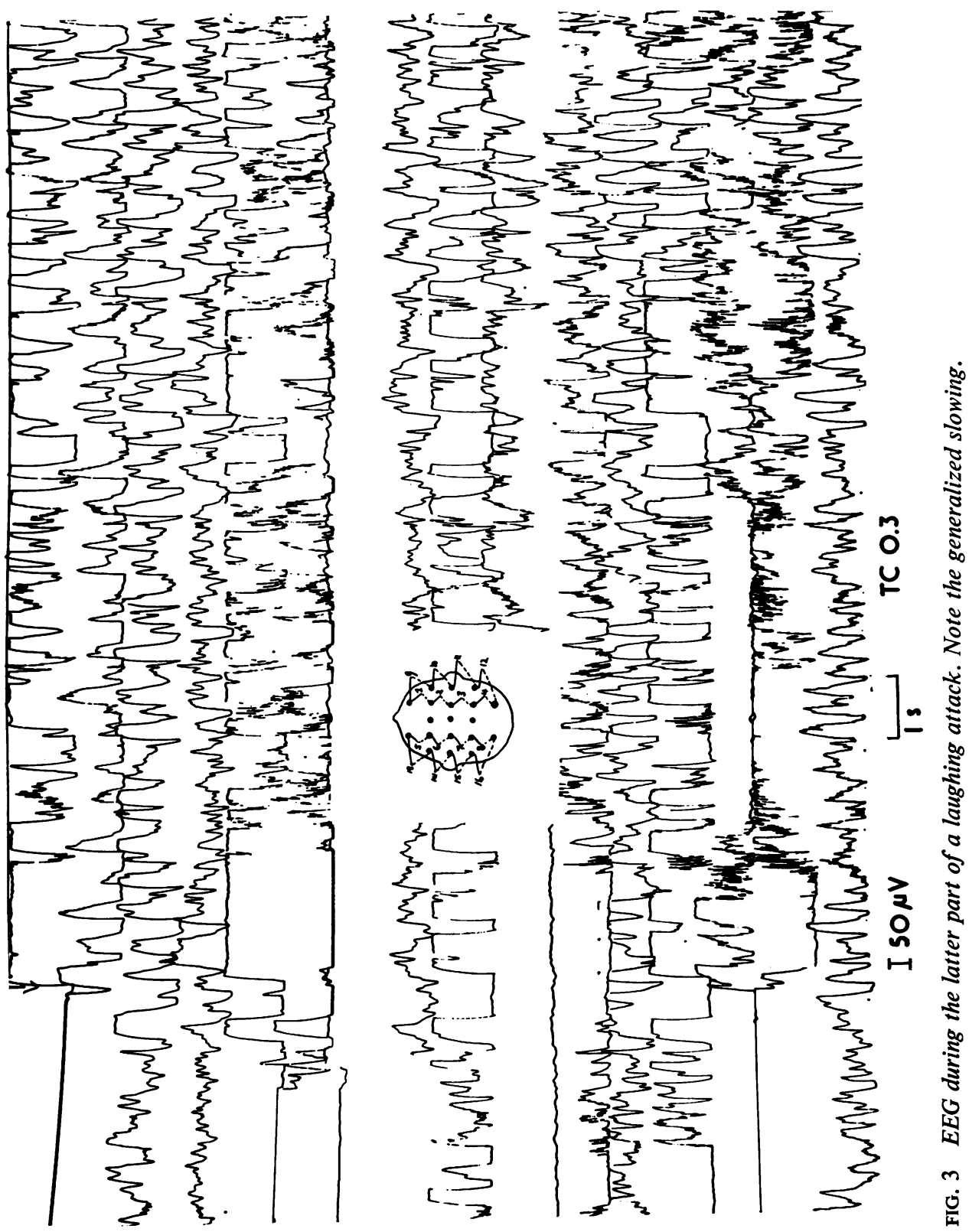

ㅁ.

옴음

므-

ర్ ฏ્

음 ำ

高

으

ฏ

을

용

읔

킁

$\stackrel{3}{3}$

훙

옥

อิ่

옥

을

N 


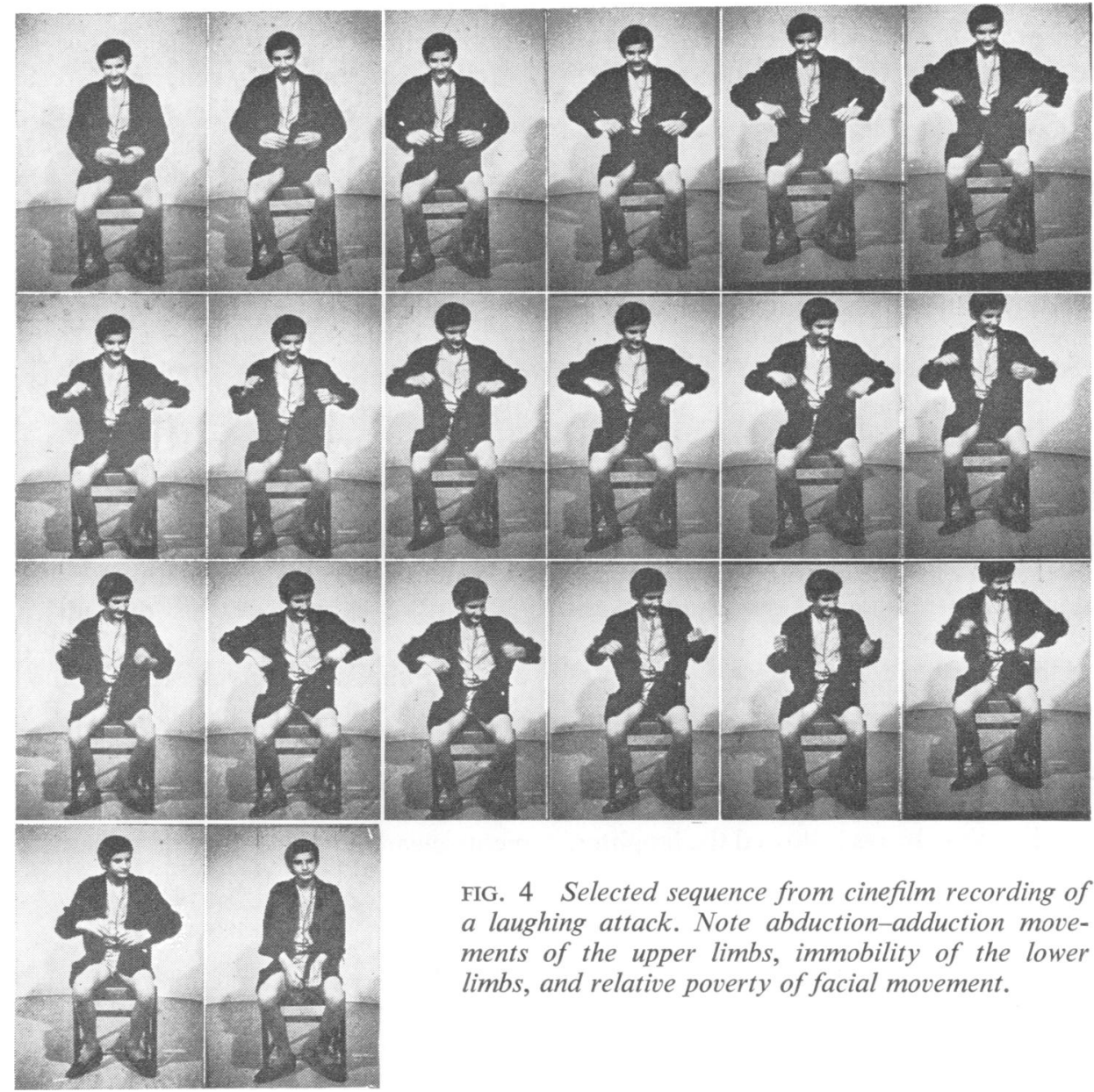

incorporation into the seizure pattern is not altogether fanciful. It is certainly less fanciful than the extraordinary suggestion that the attacks were related to masturbation. This latter view is advanced even by Martin (1950) who, in discussing epileptic laughter, states 'Some of these cases have very peculiar features and in particular in a number of them the attacks are accompanied by "orgasmolepsy", a fact which lends supports to the suggestion that the motor centres for laughter and for certain sexual motor activity may be neighbours'. No details of the 'orgasmolepsy' are given, nor whether it occurred more frequently in those patients whose ictal laughter and precocious puberty were related to hypothalamic pathology.
The verbalization was always a stereotyped repetition of a sentence or part of the sentence 'Here we go again'. This seems to indicate a remembrance of past attacks for which, however, he was completely amnesic. It suggests activation of speech and memory mechanisms and thus involvement of temporal lobe. Ictal verbalization was reported by Serafetinides and Falconer (1963) in 15 of 100 patients submitted to anterior temporal lobectomy. 'Recurrent, irrelevant and emotional utterances' occurred in 11 patients with right-sided lesions as opposed to four with left-sided lesions. Schmidt and Wilder (1969) agree that speech automatisms, for which the patient is amnesic, are more commonly of temporal lobe origin but have no lateralizing 
significance and 'may sometimes accompany petit mal automatisms' which they describe as 'vocalization or crude speech'. 'Crude speech' is not defined. Psychomotor automatisms are not only rare but are notoriously difficult to separate clinically from partial seizures of temporal lobe origin. Money and Hosta (1967) cite Foerster and Gagel (1933) as evoking hilarity and speech in a conscious patient during craniotomy by stimulating the floor of the third ventricle. However, this type of response was not ictal but related to an induced emotional state.

One patient with gelastic epilepsy in whom verbalization resembled that of our patient, was reported in a boy aged 11 years by Daly and Mulder (1957). After one of his laughing attacks, he sighed deeply and said 'Oh dear'. At operation a left temporo-occipital 'mixed oligoependymoma' was removed. Gascon and Lombroso (1971) reported a 10 year old boy with a rounded filling defect in the posterior portion of the third ventricle whose laughing attacks 'would occasionally end with automatically repeated sentences'. Unfortunately, the details are not given. In our patient, as well as these two cases, verbalization always followed the laughter.

The repetitive abduction-adduction movements that occurred as virtually an isolated motor phenomenon in our patient are not those that sometimes accompany hearty laughter. Indeed, in the only other patient with identical movements and ictal laughter that we have been able to trace in the literature, the laughter and movements occurred independently. Gascon and Lombroso (1971) reported a 5 year old child with a hypothalamic astrocytoma. Preoperative seizures took this form-

'the eyes rolled up, the head flexed, then the arms flexed at the elbows and beat symmetrically at the side like "butterfly wings". The seizure ended with the head turned to the left with a strange twisted smile. She maintained some degree of consciousness during these episodes, which occurred several times daily.' [After excision of the astrocytoma she had] 'seizures that consisted of a giggle that was partially a laugh and partially a cry. Occasionally there was left facial twitching but no other movements'.

The desynchronization and generalized slowing of the EEG while laughing is similar to that described by Gumpert et al. (1970), although other authors (Weil et al., 1958; Roger et al., 1967;
Chen and Forster, 1973) recorded focal temporal abnormalities in some of their cases.

Ictal laughter is generally regarded as 'symptomatic', but patients in whom localized cerebral pathology has been demonstrated at operation or necropsy are rare. The site of pathology in these cases has either been temporal lobe (Daly and Mulder, 1957; Loiseau et al., 1971); frontal lobe (Loiseau et al., 1971); or hypothalamus (Dott, 1938; Martin, 1950; List et al., 1958; Money and Hosta, 1967; and Gascon and Lombroso, 1971). However, in many of these cases pathological changes were also present in surrounding structures. Laughter is a complex neurophysiological event and clearly involves many neural structures. In most patients with ictal laughter analysis of the seizure pattern does not enable the clinician to localize a single lesion. We experience this difficulty with our patient but feel that the absence of clinical signs of hypothalamic involvement, the normal pneumoencephalogram, the type of verbalization, the age of onset, and the initial interictal EEG may favour primary left temporal lobe involvement, although the laughter and movements clearly involve midline structures.

\section{ADDENDUM}

When last seen in September 1974, after ethosuximide $250 \mathrm{mg}$ three times a day had been added to his medication, the patient reported that he had not had a 'laughing' attack for five months but about twice a month he would experience a 'feeling as though my head swims and I remember an incident-it is always the same but I cannot remember it afterwards. It is like a dream-it only lasts a few seconds'. His EEG was normal apart from occasional episodic left temporal abnormality.

\section{REFERENCES}

Chen, R.-C., and Forster, F. M. (1973). Cursive epilepsy and gelastic epilepsy. Neurology (Minneap.), 23, 1019-1029.

Daly, D. D., and Mulder, D. W. (1957). Gelastic epilepsy. Neurology (Minneap.), 7, 189-192.

Dott, N. M. (1938). Surgical aspects of the hypothalamus. In The Hypothalamus, p. 179. Edited by W. F. Clark, Le G. Beattie, J. Riddoch, and N. M. Dott. Oliver and Boyd: Edinburgh.

Foerster, O., and Gagel, O. (1933). Ein Fall von Ependymcyste des III. Ventrikels. Zeitschrift für die gesamte Neurologie und Psychiatrie, 149, 312-344. 
Gascon, G. G., and Lombroso, C. T. (1971). Epileptic (gelastic) laughter. Epilepsia, 12, 63-76.

Gumpert, J., Hansotia, P., and Upton, A. (1970). Gelastic epilepsy. Journal of Neurology, Neurosurgery, and Psychiatry, 33, 479-483.

Ironside, R. (1956). Disorders of laughter due to brain lesions. Brain, 79, 589-609.

List, C. F., Dowman, C. E., Bagchi, B. K., and Bebin, J. (1958). Posterior hypothalamic hamartomas and gangliogliomas causing precocious puberty. Neurology (Minneap.), 8, 164-174.

Loiseau, P., Cohadon, F., and Cohadon, S. (1971). Gelastic epilepsy. A review and report of five cases. Epilepsia, 12, 313-323.

Martin, J. P. (1950). Fits of laughter (sham mirth) in organic cerebral disease. Brain, 73, 453-464.

Money, J., and Hosta, G. (1967). Laughing seizures with sexual precocity. Report of two cases. Johns Hopkins Medical Journal, 120, 326-336.

Rey-Pias, J. M. (1972). Gelastic epilepsy (laughing seizures).
Schweizer Archiv für Neurologie, Neurochirurgie und Psychiatrie, 111, 29-35.

Roger, J., Lob, H., Waltregny, A., and Gastaut, H. (1967). Attacks of epileptic laughter; on 5 cases. Electroencephalography and Clinical Neurophysiology, 22, 279.

Serafetinides, E. A., and Falconer, M. A. (1963). Speech disturbances in temporal lobe seizures: a study in 100 epileptic patients submitted to anterior temporal lobectomy. Brain, 86, 333-346.

Schmidt, R. P., and Wilder, B. J. (1968). Epilepsy, pp. 14 and 28. Davis: Philadelphia.

Swash, M. (1972). Released involuntary laughter after temporal lobe infarction. Journal of Neurology, Neurosurgery, and Psychiatry, 35, 108-113.

Trousseau, A. (1873). Clinique Médicale de l'Hôtel-Dieu de Paris, 4th edn, p. 409. Baillière: Paris.

Weil, A. A., Nosik, W. A., and Demmy, N. (1958). Electroencephalographic correlation of laughing fits. American Journal of Medical Science, 235, 301-308. 